\title{
CNS changes in Usher's syndrome with mental disorder: CT, MRI and PET findings
}

\author{
JUNZO KOIZUMI, * KOJIRO OFUKU,* KENICHI SAKUMA,* \\ HIROYASU SHIRAISHI, * MASAAKI IIO, $†$ SHIGERU NAWANO
}

From the Department of Psychiatry, Institute of Clinical Medicine, the University of Tsukuba, ${ }^{*}$ National Chest Hospital, $\uparrow$ the Department of Radiology, School of Medicine, Chiba University, $\ddagger$ Japan

SUMMARY CNS changes in a case of Usher's syndrome associated with schizophrenia-like mental disorder were observed by CT, MRI and PET. The neuro-radiological findings of the case demonstrate the degenerative and metabolic alterations in various regions of cortex, white matter and subcortical areas in the brain. Mental disorder of the case is almost indistinguishable from that of schizophrenia, but the psychotic feature is regarded as an atypical or mixed organic brain syndrome according to the classification in the third edition of the American Psychiatric Association's Diagnostic and Statistical Manual of Mental Disorders (DSM-III).

Von Graefe ${ }^{1}$ and Liebreich ${ }^{2}$ reported the simultaneous occurrence of retinitis pigmentosa and congenital deafness. Usher ${ }^{3}$ emphasised the inheritance of retinitis pigmentosa and noted some cases with mental disorders and deafness.

Various mental disorders associated with Usher's syndrome, including schizophrenia-like disorder, atypical psychosis, recurrent depressive illness, neurotic disorder and mental deficiency have been reported. ${ }^{3-12}$ In these reports, two aetiological factors of mental disorders associated with Usher's syndrome have been suggested. One is the stress-related illness imposed by progressive sensory impairment, the other is the direct consequence of a cerebral lesion. However, the cause of psychiatric symptoms in Usher's syndrome remains unclear.

We report a study of a case of Usher's syndrome associated with schizophrenia-like disorder by CT, MRI and PET in order to assess the CNS involvement. An assessment by conventional CT of Usher's syndrome has been reported to show cerebellar and occipital atrophy; ${ }^{13}$ however, no other study to our knowledge has examined patients with Usher's syndrome with MRI and PET.

Address for reprint requests: Junzo Koizumi, MD, Professor of Psychiatry, Institute of Clinical Medicine, The University of Tsukuba, Tsukuba City, Ibaraki 305, Japan.

Received 21 July 1987 and in revised form 8 January 1988. Accepted 23 January 1988

\section{Case report}

A 44 year old male with hearing loss, visual disturbance and schizophrenia-like mental disorder was admitted to the psychiatric ward, Tsukuba University Hospital, in October, 1984. At the age of 15 years he had begun to suffer from visual and auditory disturbances. He had suffered from night-blindness and ataxic gait disturbance since the age of 37 years. In May, 1984, at the age of 43 years there was behavioural deterioration and personality changes with delusions of persecution and poisoning, auditory hallucinations and psychomotor excitement. In October, 1984, he was diagnosed as suffering from schizophrenia. He was referred to Tsukuba University Hospital for ophthalmological, otological and psychiatric examination.

His visual and auditory disturbances were found to be due to retinitis pigmentosa and sensorineural deafness with a 50 $\sim 70 \mathrm{~dB}$ bilateral sensorineural hearing loss. Prominent psychiatric symptoms were blunting of affect, autism, command hallucinations of voices speaking for him to leave hospital and persecutory delusions of his estate stolen by others. Cerebellar testing demonstrated a wide-based ataxic gait, hypermetria on heel-knee testing and finger-to-nose dysmetria. Neurological findings were otherwise normal. From these features, the patient was diagnosed as Usher's syndrome with a schizophrenia-like disorder.

CT showed various degrees of diffuse cortical atrophy and periventricular low density areas around the anterior horns, prominent enlargement of the fourth ventricle and ambient cistern and cerebellar hemispheric atrophy; in addition, there was calcification in the globus pallidus on each side.

The MRI was performed with a Picker International Vista-MR system, with a 0.5 tesla superconducting magnet 

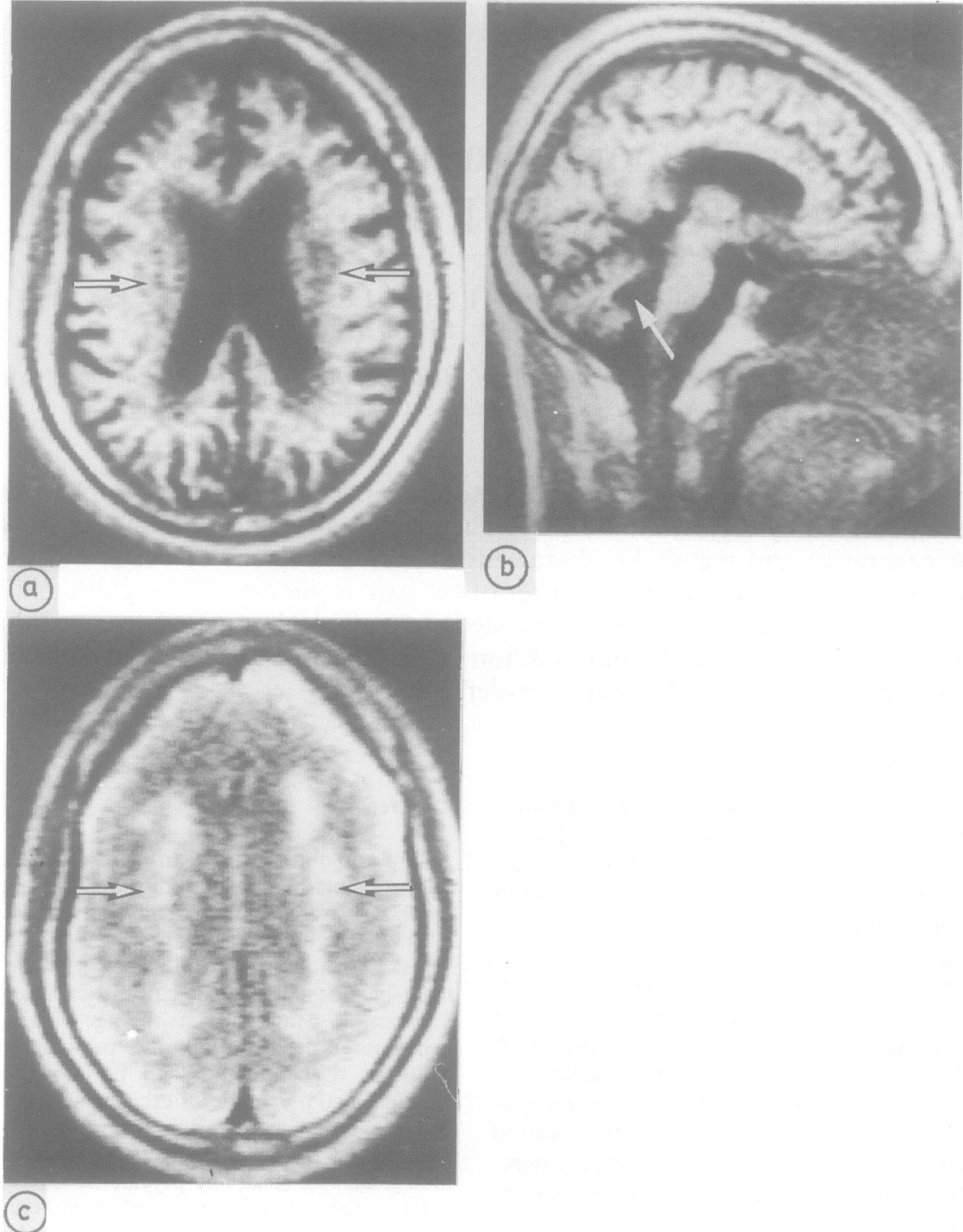

Fig 1 MRI of the brain. (a) Diffuse cortical atrophy, ventricular dilatation and multiple low density foci surrounding ventricles (arrows). (b) Dilatation of fourth ventricle (arrow) and thining corpus callosum. (c) Diffuse periventricular high intensity (arrows) with irregular lateral margins (text for explanation).

operating at $\mathbf{0 . 2 6}$ tesla (fig 1); spin echo (SE) and inversion recovery (IR) techniques were used. T1-weighted axial image $(\mathrm{IR} ; \mathrm{TR}=2080 \mathrm{~ms}, \mathrm{~T} 1=500 \mathrm{~ms})$ demonstrated brain atrophy and multiple low intensity foci surrounding the ventricles. T1-weighted sagittal image (IR) showed a dilated fourth ventricle and a thin corpus callosum. T2-weighted axial image (SE; TR $=2000 \mathrm{~ms}$, TE $=80 \mathrm{~ms}$ ) showed diffuse periventricular high intensity with irregular lateral margins.
PET images were recorded of regional cerebral blood flow (CBF), oxygen extraction fraction (OEF), and cerebral oxygen consumption $\left(\mathrm{CMRO}_{2}\right)$ by the steady state technique using ${ }^{15} \mathrm{O}_{2}$ and $\mathrm{C}^{15} \mathrm{O}_{2}$ (fig 2, table). The PET study revealed generalised reduction of $\mathrm{CBF}$ and $\mathrm{CMRO}_{2}$ in the whole of cortex and subcortex, expecially in the pallium, but in the basal ganglia $\mathrm{CBF}$ and $\mathrm{CMRO}_{2}$ were relatively preserved. The OEF was within normal limits in all areas. 

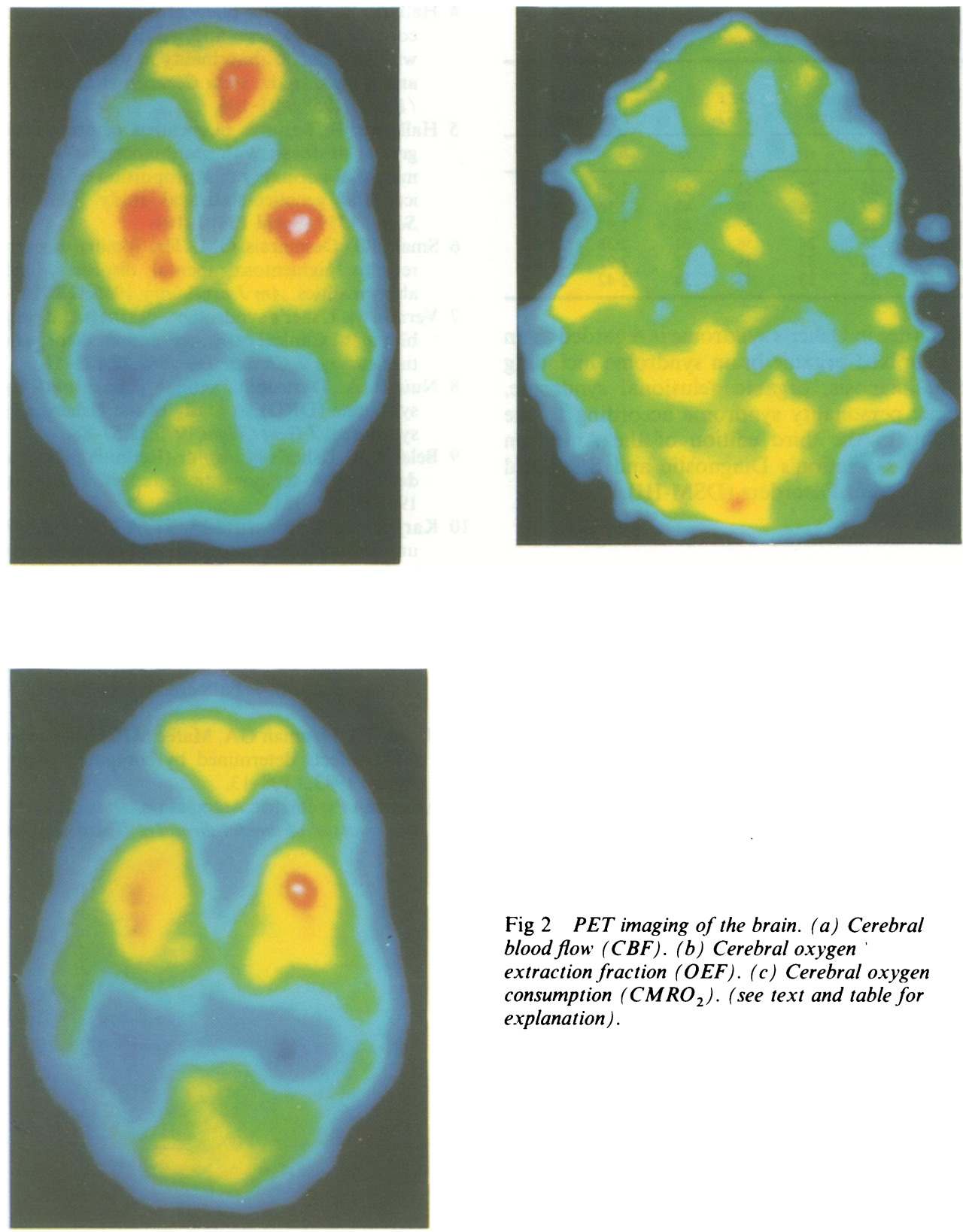

Fig 2 PET imaging of the brain. (a) Cerebral blood flow (CBF). (b) Cerebral oxygen extraction fraction $(O E F)$. (c) Cerebral oxygen consumption $\left(\mathrm{CMRO}_{2}\right)$. (see text and table for explanation).

\section{Discussion}

Bloom et $\mathrm{al}^{13}$ demonstrated cerebellar atrophy by CT in six of 12 patients with Usher's syndrome. Of these patients, three also showed occipital lobe atrophy. But no signs of cerebellar and occipital dysfunction were noted. They suggested that these CNS defects may be among the pleiotropic effects of the Usher's

syndrome gene. No other neuroradiological studies on the CNS of Usher's syndrome have been previously reported in detail.

The CT, MRI and PET findings in the present case suggest that Usher's syndrome is a metabolic and degenerative disorder in the whole brain, especially in the subcortical areas and white matter in the cerebrum as well as in the cerebellum. A schizophrenia-like 
Table Values of regional measurements with PET in the brain of a case of Usher's syndrome

\begin{tabular}{|c|c|c|c|c|c|c|}
\hline \multirow[b]{2}{*}{ Regions } & \multicolumn{2}{|c|}{$\begin{array}{l}r C B F \\
(\mathrm{ml} / 100 \mathrm{~g} \\
\mathrm{brain} / \mathrm{min})\end{array}$} & \multicolumn{2}{|c|}{$\begin{array}{l}O E F \\
(\%)\end{array}$} & \multicolumn{2}{|c|}{$\begin{array}{l}C M R O_{2} \\
\left(\mathrm{ml} / 100^{2} \mathrm{~g}\right. \\
\text { bain } / \mathrm{min})\end{array}$} \\
\hline & $l t$ & $r t$ & $l t$ & $r t$ & $l t$ & $r t$ \\
\hline $\begin{array}{l}\text { Frontal lobe } \\
\text { Parietal lobe } \\
\text { Temporal lobe } \\
\text { Occipital lobe } \\
\text { Caudate nucleus } \\
\text { Thalamus }\end{array}$ & $\begin{array}{l}23 \\
27 \\
22 \\
26 \\
38 \\
35\end{array}$ & $\begin{array}{l}25 \\
26 \\
25 \\
24 \\
37 \\
33\end{array}$ & $\begin{array}{l}51 \\
50 \\
57 \\
58 \\
48 \\
43\end{array}$ & $\begin{array}{l}50 \\
48 \\
46 \\
61 \\
51 \\
54\end{array}$ & $\begin{array}{l}1 \cdot 80 \\
2 \cdot 16 \\
1 \cdot 97 \\
2 \cdot 38 \\
2 \cdot 92 \\
2 \cdot 42\end{array}$ & $\begin{array}{l}1.96 \\
2.00 \\
1.80 \\
2.31 \\
3.01 \\
2.81\end{array}$ \\
\hline
\end{tabular}

mental disorder in Usher's syndrome is regarded as an atypical or mixed organic brain syndrome including organic hallucinosis, organic delusional syndrome, and organic personality syndrome according to the classification in the third edition of the American Psychiatric Association's Diagnostic and Statistical Manual of Mental Disorders (DSM-III). ${ }^{14}$

\section{References}

1 Von Graefe A. Exceptionelles Verhalten des Gesichtsfeldes bei Pigmententartung der Netzhaut. von Graefes Arch Klin Exp Ophthalmol 1858;4:250-3.

2 Liebreich R. Alkunft aus Ehen unter Blutsverwandten als Grund von Retinitis pigmentosa. Dtsch Klin $1861 ; 6: 53-55$.

3 Usher $\mathrm{CH}$. On the inheritance of retinitis pigmentosa, with notes of cases. $R$ Lond Ophthalmol Hosp Rep 1914;19:130-236.
4 Hallgren B. Retinitis pigmentosa in combination with congenital deafness and vestibulocerebellar ataxia; with psychiatric abnormality in some cases. A clinical and genetic study. Acta Genetica et Statistica Medica (Basel) 1958;8:97-104.

5 Hallgreen B. Retinitis pigmentosa combined with congenital deafness; with vestibulocerebellar ataxia and mental abnormality in a proportion of cases. A Clinical and genetico-statistical study. Acta Psychiatr Scand 1959;(Suppl 138):1-101.

6 Small JG, Desmarais GM. The familial occurrence of retinitis pigmentosa, mental disorders, and EEG abnormalities. Am J psychiatry 1966;122:1286-9.

7 Vernon M. Usher's syndrome-deafness and progressive blindness. Clinical cases, prevention, theory and literature survey. J Chronic Dis 1969;22:133-51.

8 Nuutila A. Dystrophia retinae pigmentosa-dysacusis syndrome (DRD): A study of the Usher-or Hallgren syndrome. J Genet Hum 1970;18:57-88.

9 Belal A Jr. Usher's syndrome (Retinitis pigmentosa and deafness). A temporal bone report. L Laryngol Otol 1975;89:175-181.

10 Karjalainen S, Teräsvirta M, Kärjä J, Kääriäinen $H$. An unusual otological manifestation of Usher's syndrome in four siblings. Clin Genet 1983;24:273-9.

11 Mangotich M, Misiaszek J. Atypical psychosis in Usher's syndrome. Psychosomatics 1983;24:674-5.

12 Eikmeier G, Dieffenbach R. Paranoide Psychose bei angeborener Taubheit und Retinopathia pigmentosa (Usher-Syndrom), Fallbericht. Nervenarzt 1984;55: 269-70.

13 Bloom TS, Fishman GA, Mafee MF. Usher's syndrome: CNS defects determined by computed tomography. Retina 1983;3:108-13.

14 American Psychiatric Association. Diagnostic and statistical manual of mental disorders. Third Edition 1980. 